\title{
Articulando ensino e pesquisa: construindo uma proposta de capacitação para docentes do ensino técnico
}

\author{
Linking teaching and research: \\ establishing a proposal for training \\ polytechnic school faculty
}

Vitoria Vellozo 1

Maria Inês C. Martins 1

Rejane B. do Nascimento 1

\footnotetext{
${ }^{1}$ Escola Politécnica de Saúde Joaquim Venâncio, Fundação Oswaldo Cruz. Av. Brasil 4365, Manguinhos, Rio de Janeiro, $R J$ 21045-900, Brasil.
}

\begin{abstract}
Based on the experience of a teacher training program entitled Program for Continuing Education of Polytechnic Faculty (PAETEC) developed by the Escola Politécnica de Saude Joaquim Venâncio (EPSJVIFIOCRUZ), this article is intended to contribute to the discussion of alternatives for continuing vocational teacher education programs. In the search for new onthe-job teacher training models fostering interaction between the educational process and research activity, the experience employs a strategy based on the construction of an integrated methodology allowing teachers to reflect on their own practices and turn them into the object of their research.
\end{abstract}

Key words Health Education; Vocational Education; Faculty; Teaching

Resumo O presente artigo visa contribuir para reflexão acerca das alternativas de capacitação e qualificação de docentes atuantes no ensino técnico, com base na experiência do Programa de Aperfeiçoamento do Ensino Técnico (PAETEC), desenvolvido pela Escola Politécnica de Saúde Joaquim Venâncio (EPSJVIFIOCRUZ). O PAETEC busca a renovação das práticas de aperfeiçoamento profissional, no próprio local de trabalho, de forma a possibilitar maior interação entre processos educacionais e atividade de pesquisa. Para tanto, utiliza como estratégia uma metodologia integradora que permite ao professor refletir sobre sua própria prática, transformandoa em objeto de investigação.

Palavras-chave Educação em Saúde; Educação Vocacional; Docente; Ensino 


\section{Introdução}

Temos como preocupação, nesta apresentação, colocar nosso entendimento sobre o contexto em que se inserem as transformações recentes na organização e nas relações de trabalho. Partimos da premissa de que o mundo do trabalho, em que pese às mudanças técnico-científicas que nele vêm se operando, realiza-se no mundo da vida.

Nessa perspectiva, a intelectualização do trabalho, seu caráter interdisciplinar e a capacidade de decidir e inovar, requisitos para o trabalhador moderno, constituem-se em desafios para as propostas de qualificação que têm por referência os trabalhadores como os principais sujeitos do processo de trabalho, ainda que a natureza deste esteja mudando. Desse modo, devidamente contextualizadas e politizadas, essas propostas, além de instrumento de flexibilização dos trabalhadores aos novos modelos de organização do trabalho, podem e devem ter um caráter de transformação e reflexão sobre as práticas profissionais.

Assim, tomando por base as diferentes dimensões do processo de qualificação, buscamos analisar a experiência de um programa de aperfeiçoamento do ensino técnico formulado e desenvolvido pela Escola Politécnica de Saúde Joaquim Venâncio (EPSJV), cujo eixo é a articulação ensino-pesquisa, como uma estratégia de capacitação de docentes atuantes no ensino técnico em saúde.

Como uma unidade técnico-científica da Fundação Oswaldo Cruz/Ministério da Saúde, a EPSJV tem como campo específico o ensino médio em saúde. Seu desafio é desenvolver, aplicar e partilhar modelos de formação e atualização técnica e científica para o nível médio na área de Ciência e Tecnologia em saúde.

Balizada no potencial técnico e pedagógico, comum a todas as unidades da Fundação Oswaldo Cruz (FIOCRUZ), a Escola Politécnica desenvolve atividades de ensino, pesquisa e extensão, atuando em duas vertentes: a qualificação e o treinamento para profissionais de saúde já inseridos no mercado de trabalho e a formação de quadros para ingresso na área. Na primeira vertente, os programas de ensino são destinados prioritariamente aos trabalhadores que atuam nas esferas públicas municipal, estadual e federal; a segunda vertente possibilita à Escola Politécnica oferecer o curso técnico de segundo grau (atual nível médio), no qual os alunos, por um período de quatro anos, recebem formação geral e profissionalizante, sendo esta última realizada nos diferentes departamentos e laboratórios de outras unidades técnico-científicas da FIOCRUZ. Nesse sentido, a EPSJV reúne, de maneira singular, elementos para implementação de um programa efetivo de articulação ensino e pesquisa no cotidiano do trabalho dos docentes, conforme buscaremos demonstrar a seguir.

\section{A formação técnica e a capacitação docente: articulando ensino e pesquisa}

Entendemos o trabalho como uma ação humana, que tem como elementos constituintes: o objeto desta ação, os instrumentos materiais e os saberes historicamente construídos. Desse modo, a discussão sobre formação técnica para o trabalho passa, necessariamente, pela identificação dos atores envolvidos, bem como pela natureza do trabalho e dos saberes que informam a sua prática.

Para Rogério Valle, formar para o trabalho, ou seja, profissionalizar, tem como ponto de partida "a capacitação do indivíduo para o desempenho de um trabalho não como reprodutor de numerosas tarefas, mas como senhor da técnica, nos níveis práticos, e conhecedor de suas potencialidades e sua competência criativa, de forma a ser um trabalhador competente, capaz de criar e recriar em cima do que faz" (Valle, 1997). Assim, é possível tomar as escolas técnicas como locus privilegiado para que se opere a mediação dos saberes inscritos na sociedade as ciências, as técnicas específicas e o trabalho.

Esse aspecto torna-se central quando se observa o universo onde se encontram profissionais de saúde, referenciados por uma prática em que "os conceitos aparecem, se definem, são aplicados e se transformam” (Peduzzi, 1997). Por um lado, a prática cotidiana dos trabalhadores de nível médio em saúde afasta-os do mundo científico; por outro, os professores, que respondem pela formação geral, estão distantes de sua aplicabilidade no mundo do trabalho. Que saberes estão contidos em determinadas práticas? Que ciências e princípios científicos os informam? Essas são questões que se colocam para os professores e que constituemse na base para o diálogo e para a aproximação desses dois mundos.

O professor, para nós, apresenta-se como ator-chave dessa interlocução. Estimular e capacitar os docentes a exercerem esse papel é o desafio a ser enfrentado quando se pretende transformar o espaço escolar em produtor e não apenas em reprodutor de conhecimento.

Nossa experiência está centrada na articulação ensino-pesquisa no ensino técnico que, em última instância, recupera o mundo do tra- 
balho e o mundo da ciência, identificando-os como espaços possíveis de se intercambiarem. Acreditamos que, ao transformar o objeto de ensino em objeto de reflexão, estaremos promovendo e qualificando os docentes, tanto na dimensão técnica especializada, quanto na dimensão sócio-política, na direção da interdisciplinaridade, questões fundamentais do conhecimento contemporâneo.

A necessidade de articulação da pesquisa e do ensino é uma discussão que vem acontecendo entre os grupos mais progressistas, no campo da educação e da ciência, desde a década de 50. A reforma universitária, em 1968, introduz a pesquisa na universidade, consolidando esta como espaço formador e referência de ensino de nível superior (Durham, 1993). Entretanto, o desenvolvimento das pesquisas, o modelo de financiamento que as orienta e a própria forma como são estruturadas nas instituições de ensino superior acabam por circunscrever as atividades de pesquisa aos programas de Pós-Graduação. Ao concluir a graduação, o mestrado e o doutorado passam a ser o caminho para aqueles que desejam seguir a carreira científica. No entanto, os que não desejam fazê-lo, sobretudo, os professores de nível médio que, raramente, tornam-se pesquisadores, mas têm no conhecimento o objeto de sua prática, vêem-se alijados do processo de produção de conhecimento.

No cotidiano, o que se observa é uma separação da produção e do consumo do conhecimento; o reforço ao caráter reprodutivo do ensino; o ensino situado num patamar inferior à pesquisa, quando, paradoxalmente, é ele que deveria formar para a pesquisa; e, finalmente, observa-se um descompromisso com a formação de profissionais críticos, que possam intervir no seu próprio processo de trabalho. Em síntese: “É comum o professor que apenas ensina, em especial o de 1o e 2o graus: estuda uma vez na vida, amealha certo lote de conhecimentos e, a seguir, transmite aos alunos, dentro da didática reprodutiva e cada dia mais desatualizada..." (Demo, 1996:12).

Como reverter esse quadro? Como desenvolver uma aprendizagem crítica e investigadora, num contexto em que a produção de conhecimento e seu consumo estão historicamente separados? Como garantir a incorporação dos resultados dos processos de investigação e de desenvolvimento científico, numa conjuntura educacional onde os professores não têm acesso às atividades de pesquisa e investigação? Que pesquisa é essa que se encerra nos seus muros? E que ensino é esse voltado para resolução mecânica de problemas e para reprodução de técnicas?
As questões colocadas no cotidiano das instituições públicas de ensino são resultado interativo de uma pluralidade de condições, de processos não lineares, que estão por demandar uma dupla referência do ponto de vista da investigação, isto é, um percurso analítico balizado na interpretação sobre as relações sociais, com base em microfundamentos, que se inscrevem nos espaços públicos, e o levantamento sobre demandas e modelos de capacitação de recursos humanos nesta área.

Assim, tomar os processos de ensino e pesquisa como partes indissociáveis da experiência de construção de conhecimento impõe o resgate das relações que se estabelecem nessa busca, uma vez que as interações entre ensino e pesquisa não são dadas, dependem de um esforço de socialização, de trocas contínuas, cujo eixo básico deve ter por referência a qualificação do ensino e da pesquisa (Martins et al., 1996).

É preciso ressaltar que o discurso da articulação ensino-pesquisa, muitas vezes, é prontamente assimilado, porém não é suficiente para revitalizar as práticas pedagógicas. Ao discutir o princípio de indissociabilidade ensino-pesquisa, Paoli (1988:51) aponta com propriedade que a afirmação desse princípio "enquanto regra geral ou normativa, pode ter um significado importante, mas corre o perigo de ser uma afirmação no vazio, caso não seja contextualizada como um processo de construção, cuja realização depende de uma série de situações complexas" (Paoli, 1988:51).

Portanto, é preciso recuperar as relações ensino-pesquisa como objeto de decisão e não apenas como afirmação de um princípio. Inserir a prática de pesquisa nas atividades de ensino no cotidiano da EPSJV tem como corolário a criação de responsabilidades na produção e transmissão de conhecimentos.

Nessa perspectiva, acreditamos, insere-se o Programa de Aperfeiçoamento do Ensino Técnico (PAETEC), cujas metas apontam para a consolidação da integração entre processos educacionais e produção de conhecimento, solidificando a EPSJV, unidade de ensino e pesquisa da FIOCRUZ, como um espaço de referência para a formação de recursos humanos de nível médio na área de saúde.

O que é o PAETEC?

Para nós, trata-se de uma nova postura em relação ao processo de ensino-aprendizagem, que implica problematizar a realidade e mobilizar para a ação conjunta, na busca de soluções para problemas significativos levantados por professores e alunos. Assim, produzir conhecimento nessa direção tem o significado de promover um processo permanente de trocas, não 
aceitando como acabados ou como fim em si mesmos os conteúdos transmitidos na escola.

Nas palavras de seus formuladores: "O PAETEC caracteriza-se, também, como uma oportunidade para o aperfeiçoamento profissional no próprio espaço de trabalho, através da capacitação dos professores enquanto 'pesquisadores em ação', já que combina a prática docente e sua reflexão à metodologia e à investigação acadêmica na compreensão sobre os processos envolvidos na educação politécnica dirigida à formação na área de saúde" (Struchiner \& Martins, 1994:1).

Criado em 1994 pela equipe dirigente da EPSJV, o Programa recupera a relação ensinopesquisa como objeto de decisão político-institucional e não apenas como afirmação de um princípio; suas metas apontam para a consolidação entre processos educacionais e produção de conhecimento, solidificando essa unidade de ensino e pesquisa da FIOCRUZ como um espaço de referência para a formação de recursos humanos de nível médio na área de saúde.

Avaliação realizada no primeiro semestre de 1995, pela Coordenação de Pesquisa da EPSJV, apontou como questões-chave para o Programa: a necessidade de promover discussões temáticas e espaços de troca; a necessidade de encontrar respostas para a heterogeneidade de formação dos pesquisadores e para as demandas de redefinição dos objetos de estudo, visando a uma maior aproximação com as práticas pedagógicas desenvolvidas; dificuldades relativas à relação com os orientadores das pesquisas; a necessidade/possibilidade de apoio técnico-metodológico (EPSJV, 1995).

Nossa contribuição junto ao PAETEC, situada no terreno das respostas às reivindicações apresentadas nessa avaliação, teve por objetivo identificar pontos críticos no processo de desenvolvimento dos trabalhos, com base nas diferentes dificuldades apontadas pelos professores-pesquisadores, alguns iniciantes, para execução dos projetos, buscando promover um conjunto de práticas pedagógicas (supervisões individuais, seminários internos e curso de introdução à metodologia de pesquisa). Tudo isso balizado num modelo de acompanhamento contínuo dos projetos, com vistas ao aperfeiçoamento da prática de pesquisa.

Paralelamente, sistematizamos um conjunto de instrumentos normativos de referência para o Programa: recomendações básicas para apresentação de projetos de pesquisa e de relatórios finais; normas para a orientação de trabalhos; criação de um banco de orientadores PAETEC, composto por profissionais de diversas instituições de ensino e pesquisa; e criação de uma ficha básica para apreciação dos projetos e relatórios pelo comitê de avaliação.

Atualmente, o PAETEC conta com apoio da Fundação de Amparo à Pesquisa do Rio de Janeiro (FAPERJ), convênio firmado em 1996, e tem 35 bolsas para professores-pesquisadores inseridos em cursos ou núcleos da Escola. A assinatura desse convênio pode e deve ser entendida como parte do sucesso do Programa que vem, gradualmente, incorporando à sua proposta temas como a qualificação contínua do corpo docente, a qualidade do ensino ofertado pela EPSJV e a garantia de um espaço de produção de conhecimento voltado para realidade de nível médio.

A experiência do PAETEC constitui um ponto de referência sólido para orientar pesquisas que visem trazer para o campo pedagógico alternativas que estimulem e qualifiquem a reflexão sobre o preparo e a prática do professor.

\section{Em busca de uma metodologia integradora}

Por tratar-se de uma proposta nova, a ser construída de forma interdisciplinar, traz dificuldades intrínsecas à construção de um modelo de formação profissional, necessitando adequar métodos e conteúdos à experiência pedagógica, tendo como base a reflexão sobre metodologia em sua dimensão ampliada.

Diante desse quadro, nossa tarefa tem sido potencializar o trabalho desses professorespesquisadores, fornecendo subsídios para que desenvolvam a assimilação crítica e criativa dos caminhos metodológicos que envolvem a produção de conhecimento. Visamos contribuir para aperfeiçoar a prática de pesquisa por meio da remoção de algumas barreiras, atualmente pouco investigadas, entre a metodologia e a pesquisa em desenvolvimento.

Atualmente, o conceito de metodologia tem sido amplamente discutido pela literatura; nossa preocupação central, contudo, é trabalhar os diferentes componentes que envolvem o processo de construção de uma dada metodologia de investigação para além das concepções descritivas que retraduzem o termo metodologia para designar tão-somente os métodos e técnicas de pesquisa.

Concordamos com Minayo (Minayo, 1992) quando afirma que o conceito de metodologia comporta três elementos fundamentais e interrelacionados, quais sejam: as concepções teóricas que norteiam o objeto de estudo, o conjunto de técnicas de pesquisa e o potencial criativo do pesquisador. Ou seja, adotamos uma 
perspectiva crítica na qual as técnicas de pesquisa dizem respeito ao objeto em análise e devem ser consideradas no plano social e de construção do conhecimento. Está implícito nessa concepção que a abordagem metodológica é mediada pelo contexto social em que estão inseridos os pesquisadores.

As metodologias qualitativas têm se tornado, cada vez mais, imprescindíveis para a investigação em saúde. No entanto, nessa área de conhecimento, constata-se uma grande defasagem na formação de profissionais envolvidos na pesquisa em saúde, impedindo-os, por vezes, de desenvolverem uma atitude de investigação. Sendo assim, foram realizadas as seguintes atividades:

- levantamento do material já produzido acerca do PAETEC pela Coordenação de Pesquisa;

- análise das informações levantadas nos instrumentos aplicados no segundo semestre de 1995 e primeiro semestre de 1996;

- levantamento bibliográfico sobre a temática articulação ensino e pesquisa;

- apresentação aos professores-pesquisadores e discussão com eles do nosso projeto de pesquisa e apoio ao desenvolvimento do PAETEC; - revisão do Projeto com base nas demandas vocalizadas pelos docentes da EPSJV;

- sistematização do material levantado;

- organização e realização do I, II e III Seminários Internos do PAETEC;

- avaliação da experiência dos seminários, em duas modalidades: oral, durante a realização dos eventos, e escrita, via instrumento elaborado para este fim e distribuído apenas para os professores-pesquisadores ao final das sessões; - elaboração de consolidado com as principais questões abordadas nos seminários;

- organização e realização do Curso de Introdução à Metodologia da Pesquisa Social em Saúde e Educação;

- elaboração de instrumento para avaliação individual do Curso de Introdução à Metodologia da Pesquisa Social em Saúde e Educação; - avaliação oral e escrita da experiência do Curso;

- elaboração de consolidado com os principais aspectos destacados na avaliação do Curso; - supervisão individual dos Projetos PAETEC em andamento;

- produção de paper em co-autoria com as Coordenações de Ensino e Pesquisa da EPSJV.

- elaboração de normas para orientação dos trabalhos de pesquisa dos professores-pesquisadores;

- confecção de instrumentos para a criação de um banco de orientadores organizado por áreas temáticas e composto por profissionais interessados em participar da proposta de articulação ensino-pesquisa;

- elaboração de normas para confecção dos relatórios finais das pesquisas PAETEC;

- oficinas de elaboração de projetos.

No conjunto das atividades desenvolvidas, gostaríamos de destacar as dinâmicas adotadas para a realização dos seminários e do Curso de Introdução à Metodologia da Pesquisa Social em Saúde e Educação, bem como as oficinas de projetos. Destacamos, ainda, as ações de normatização do PAETEC como parte do processo de capacitação e qualificação profissional.

\section{Os seminários internos}

A realização dos seminários internos visa acompanhar, incentivar e avaliar coletivamente o processo de execução das pesquisas, constituindo-se espaços de apresentação das diferentes etapas de trabalho, contando com a participação dos professores-pesquisadores, orientadores, Coordenações de Pesquisa e Ensino, Chefias de Departamentos da EPSJV e professores convidados. Ganha centralidade nesta experiência o diálogo construtivo, o estímulo à atividade de pesquisa, o olhar crítico, as trocas de experiências e a busca de soluções para problemas comuns.

Os trabalhos dos professores-pesquisadores foram divididos em seis grupos temáticos no primeiro conjunto de seminários, a saber: Comunicação e Artes; Programa de Iniciação Científica; Registro e Informações em Saúde; Processo de Trabalho; Interdisciplinaridade; Avaliação. Todos ocorreram durante o mês de setembro de 1995, com um caráter semifechado, a fim de garantir um debate mais aprofundado dos temas em questão. O segundo bloco de seminários internos ocorreu durante o mês de abril de 1997. Utilizando-se a mesma metodologia foram organizados os seguintes grupos temáticos: Política e Administração em Saúde; Ensino de Ciências na Formação Técnica; Comunicação e Linguagem; Formação Técnica em Saúde Coletiva; Informação em Saúde; Artes e Formação Técnica; Ciências Sociais e Ensino Técnico no Segundo Grau.

Os seminários internos do PAETEC foram avaliados como uma experiência muito positiva pelos participantes, tanto por contribuir para potencializar os projetos em desenvolvimento, quanto pela possibilidade de abrir um canal efetivo para a construção de linhas de pesquisas coletivas no espaço institucional.

O crescimento e aperfeiçoamento do programa, nesses quase cinco anos, possibilitou à 
Escola estruturar suas linhas de pesquisa, em torno de eixos temáticos: Informação, Educação e Comunicação em Saúde; Vigilância em Saúde; Programas de Saúde; Gestão e Processo de Trabalho em Saúde; Educação Geral no Ensino Técnico e Fundamental; Educação em Ciências no Ensino de Nível Médio e Formação Técnica em Saúde. Assim, o III Seminário PAETEC, realizado em novembro de 1998, já organizado com base nas linhas de pesquisa, contou não só com a participação de todos os bolsistas, como também com o grupo de pesquisadores da Escola. Os trabalhos foram apresentados sob a forma de Comunicação Coordenada, com a presença de um debatedor convidado.

Os resultados apreendidos dos conjuntos de seminários apontam o desdobramento de um corpo de práticas pedagógicas - entendido como instrumento propulsionador de desenvolvimento das pesquisas, balizado num modelo de acompanhamento contínuo das produções, com ênfase no diálogo permanente como estratégia para ajuste das relações travadas entre os professores-pesquisadores, visando ao aperfeiçoamento da opção metodológica para os objetivos escolhidos por cada trabalho.

\section{Curso de introdução à metodologia da pesquisa social em saúde e educação e as oficinas de elaboração de projetos}

Como parte dessa proposta de trabalho, também vislumbramos a necessidade de oferecer aos professores-pesquisadores noções preliminares de metodologia da pesquisa social em saúde e educação, uma vez que a investigação nessas áreas, mesmo quando referenciada pelas ciências exatas ou biológicas, não pode prescindir da matriz social e cultural em que se encontram incrustadas. São objetos muito particulares, que trazem no bojo uma noção que revela a realidade sócio-cultural da qual se constituem.

O curso, realizado em julho de 1996, visou introduzir noções de metodologia da pesquisa social com base na reflexão sobre os caminhos metodológicos que o pesquisador trilha na construção de seu trabalho, buscando, portanto, ir além das concepções descritivas que retraduzem o termo metodologia como métodos e técnicas de pesquisa. Nosso objetivo foi fornecer aos professores-pesquisadores subsídio teórico-metodológico básico que os capacitasse para compreender a questão da especificidade da pesquisa social e suas implicações no campo da saúde e da educação, tornandose necessária a apresentação de conceitos fun- damentais para a compreensão do processo de construção de um corpo teórico específico. Nessa etapa do trabalho, contamos com a participação de pesquisadores do Departamento de Ciências Sociais da Escola Nacional de Saúde Pública/FIOCRUZ.

Foram ministradas sete aulas, uma por semana, com duração de duas horas cada, buscando adequar a necessidade de repasse de conteúdos mínimos e o pouco tempo disponível dos professores-pesquisadores. Adotamos uma bibliografia reduzida, porém de leitura obrigatória, e colocamos à disposição dos participantes uma vasta bibliografia complementar. Acreditamos que esse modelo simplificado garantiu a adesão ao curso, porém impediu um maior aprofundamento da temática, conforme o relatado no instrumento de avaliação preenchido pelos 'alunos' ao final do curso.

Dessa forma, a partir de discussões com grupos e gestores envolvidos com o ensino e a pesquisa, optou-se, num segundo momento, por uma estratégia que provocasse a discussão metodológica - tendo como base as questões levantadas na elaboração do projeto.

Nessa perspectiva, em janeiro e fevereiro de 1999, foram realizadas duas Oficinas de Projeto como atividade preparatória para o PAETEC III, para a qual os professores trouxeram suas questões referentes ao projeto de investigação a ser desenvolvido. Valendo-se de problemas concretos, foi possível refletir sobre objetivos, caminhos metodológicos, contexto, justificativa e resultados esperados da pesquisa.

Avaliou-se como uma dinâmica positiva e produtiva, embora os resultados estejam diretamente relacionados à realização de uma discussão prévia e à elaboração de um proposta preliminar nos espaços de referência dos professores (colegiados de cursos, programas e departamentos).

\section{Os instrumentos normativos}

A produção desses documentos teve por objetivo propiciar a criação de instrumentos de referência para os trabalhos acadêmicos desenvolvidos no âmbito do PAETEC, visando orientar a organização da produção científica dos professores-bolsistas.

Trata-se de um esforço inicial de sistematização, que não pretende ser definitivo, ao contrário, pode ser enriquecido com sugestões de conteúdo, adaptações às eventuais exigências e demandas técno-científicas e didático-pedagógicas não contempladas, e que não dispensa, necessariamente, a consulta aos manuais de 
métodos e técnicas de pesquisa, sistematizados e editados, existentes e em circulação nas bibliotecas. Nosso objetivo foi, sobretudo, auxiliar os participantes do Programa no processo de elaboração de projetos de pesquisa e relatórios finais, contribuindo, ao mesmo tempo, para a consolidação do PAETEC como uma proposta de aperfeiçoamento profissional, balizada na articulação ensino-pesquisa.

Nesta mesma linha, destacamos as recomendações em torno da orientação dos projetos de pesquisa. O material produzido para os orientadores se constitui de três partes: a primeira, sobre o Programa propriamente dito; a segunda, sobre o papel da orientação; e, finalmente, as recomendações sobre os orientadores e a orientação. O estabelecimento de um vínculo mais estreito com os orientadores se apresenta como um ponto fundamental para a qualificação dos trabalhos produzidos pelos professores-pesquisadores.

\section{Dilemas e perspectivas em torno do PAETEC}

O Programa de Aperfeiçoamento do Ensino Técnico nasce com o objetivo de fortalecer o campo do ensino, da pesquisa e da produção científica no âmbito da Escola Politécnica de Saúde Joaquim Venâncio. Destina-se a profissionais de nível superior, com atividade docente e de pesquisa no campo de ensino técnico, utilizando as atividades da Escola como objeto de intervenção e reflexão.

Suas metas estão direcionadas para a consolidação da integração entre processos educacionais e produção de conhecimento, solidificando essa unidade de ensino e pesquisa da FIOCRUZ como um espaço de referência para a formação de recursos humanos de nível médio na área de saúde.

A idéia de um programa de apoio ao Ensino Técnico desenvolve-se a partir de duas referências básicas. A primeira, de caráter conceitual, diz respeito à consolidação do modelo educacional e ao fortalecimento de práticas educativas, tidas, teoricamente, como consenso, mas pouco implementadas. Acrescenta-se a isso a necessidade de se identificar e consolidar o espaço da pesquisa na Escola, considerando seu papel dentro da FIOCRUZ, bem como de aprofundar teoricamente e acumular conhecimentos em relação ao projeto de educação da EPSJV, sendo, portanto, necessário construir uma metodologia de trabalho que permita a formação e o desenvolvimento dos professores no campo da Ciência e da Técnica.
A outra referência, que marca as origens dessa proposta como um programa institucional, foi a necessidade de redefinir as relações de trabalho do corpo docente da Escola. A modalidade professor horista, alternativa que possibilitou à Escola estruturar-se e construir-se, numa conjuntura político-administrativa adversa, enfrentada pelas instituições públicas federais na área de recursos humanos, não respondia às necessidades tanto do projeto institucional, como daqueles trabalhadores que se envolveram nesse desafio. Era necessário, por um lado, promovê-los tecnicamente e preparálos para assumir a execução de projetos de pesquisa e, por outro, buscar formas institucionais de mantê-los em suas atividades pedagógicas. Nesse sentido, o Programa caracterizase como específico e institucional, destinado ao aperfeiçoamento dos docentes/pesquisadores e do conhecimento produzido na tarefa de ensinar, com as características inerentes ao perfil da Escola.

Cada projeto tem a duração de 24 meses, dividido em dois módulos de 12 meses. Os projetos são avaliados a cada 12 meses, por meio da comparação dos planos de trabalhos e dos relatórios dos participantes, mediada pela avaliação das atividades departamentais onde estão inseridos.

A equipe executora do Programa é composta pela Coordenação de Pesquisa, Coordenação Administrativa, Coordenação de Ensino, Chefias de Departamento e Núcleos. As coordenações se responsabilizam pelo acompanhamento direto das atividades, de acordo com o conteúdo definido no Projeto.

A avaliação é feita por um comitê $a d-h o c$ formado por dois representantes da Escola Politécnica de Saúde Joaquim Venâncio (Coordenador de Pesquisa e Coordenador de Ensino); dois membros externos à Escola, indicados pelo Conselho Deliberativo da Unidade nas áreas de formação em Ciência e Tecnologia em Saúde e formação para os Serviços de Saúde; e um representante da FAPERJ.

O PAETEC II (biênio 96/98) contou com 28 professores-pesquisadores, 24 orientadores (sendo dez doutores, 13 mestres e um bacharel em teatro) envolvidos com o desenvolvimento de 24 projetos de pesquisa, nas áreas de educação, saúde, ciência e tecnologia. A Figura 1 apresenta as áreas contempladas, segundo critérios de enquadramento propostos pela FAPERJ.

Conjugar as atividades de ensino com as atividades de investigação tem se mostrado, na prática, um grande desafio para o grupo de professores. A internalização de uma nova maneira de enfocar o ensino e a pesquisa, baliza- 
Figura 1

Áreas contempladas com bolsas do convênio FIOCRUZ/FAPERJ, biênio 96/98 PAETEC II.

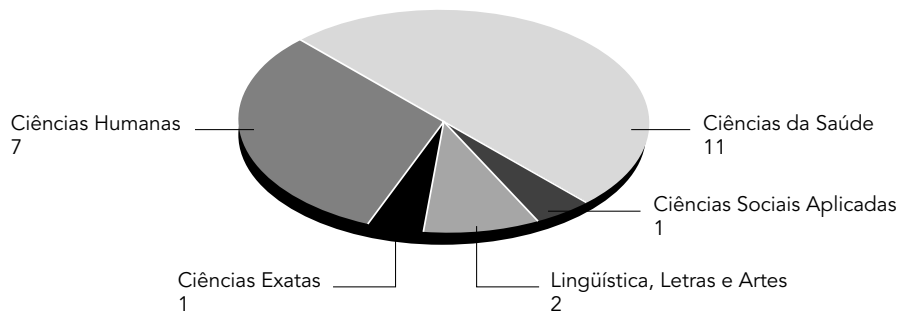

Figura 2

Formação acadêmica do quadro docente PAETEC II.

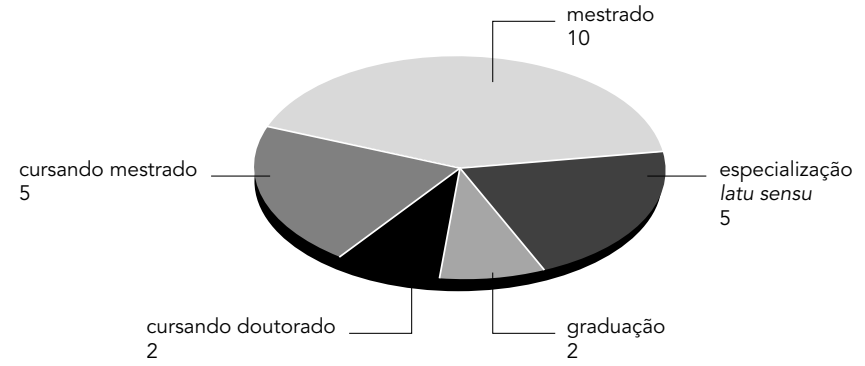

Figura 3

Relatórios finais PAETEC I.

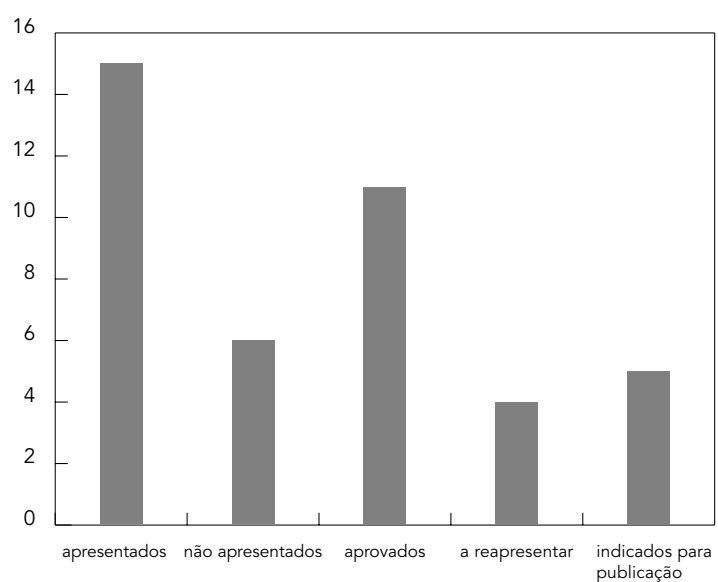

da no princípio de indissociabilidade das atividades de ensino e de pesquisa, bem como a necessidade de mudanças no processo de trabalho, coloca-nos diante da difícil tarefa de construir, no cotidiano institucional, uma prática de ensino que seja dinamicamente realimentada, reorientada e reconduzida pela produção científica dos professores.

Nesse sentido, as propostas de trabalho desenvolvidas junto aos professores-pesquisadores têm como referência as contradições que perneiam a concretização dessa experiência, assim como a clareza de que as atividades implementadas, mesmo quando aparentemente de reduzido alcance ou baixa penetração no grupo, acabam por revelar novos desdobramentos.

Dois aspectos podem ser reveladores do potencial mobilizador do Programa: a participação dos professores em congressos e seminários e o ingresso dos mesmos em cursos de mestrado ou doutorado em 1996 e 1997. A Figura 2 apresenta a titulação acadêmica dos professores PAETEC II.

Reconhecemos que os instrumentos elaborados para captar a dinâmica implementação do PAETEC, não raro, mostram-se inadequados para a apreensão do conjunto de questões levantadas, impondo-nos o desafio constante de (re)criar a metodologia de trabalho.

A questão tempo aparece como um aspecto crucial para a análise do desenvolvimento dos trabalhos do PAETEC. Enquanto queixa constante, aponta a necessidade de uma proposta de normatização criativa do andamento das pesquisas, revelando, simultaneamente, ambigüidades vividas no cotidiano institucional. E não poderia ser diferente, afinal, trata-se de pôr em prática o desafio de articular ensino e pesquisa.

A defasagem entre intenções e realizações fica evidente quando se procede a uma análise do que foi efetivamente conseguido na primeira fase do Programa (PAETEC I - biênio 94/96): foram apresentados 24 projetos de pesquisas, 15 relatórios finais, oito professores foram desligados e apenas cinco relatórios finais foram recomendados para publicação pelo Comitê de Avaliação (Figura 3).

A maioria dos projetos PAETEC I não nasceu com clareza de propósitos, além dos legal e formalmente estabelecidos, daí a fragilidade de alguns projetos traduzida no fracasso dos relatórios finais. Não obstante, essa fase constituiu um espaço de amadurecimento essencial para a consolidação do Programa em seu formato atual, PAETEC II, cujo sucesso se expressa na institucionalização do Programa mediante o 
convênio com a FAPERJ e no incremento da produção acadêmica da EPSJV. No biênio 19961998, foram finalizados 23 Projetos de Pesquisa, sendo nove deles indicados para publicação por examinadores ad hoc, e ainda seis estudos encontram-se em andamento com finalização prevista para junho de 2000.

O PAETEC III, iniciado em março (1999 a 2001), procura aprofundar a dimensão institucional do Programa através do fortalecimento de suas linhas de pesquisa, estimulando a associação entre projeto institucional, prioridades na área de educação e de saúde e qualificação do corpo técnico. A expectativa é de que a acumulação e o amadurecimento obtidos com esse programa se traduzam no aumento da produção científica da Escola, que, em última instância, induz e possibilita a sistematização e a especialização das experiências pedagógi- cas desenvolvidas pela Escola Politécnica de Saúde Joaquim Venâncio da FIOCRUZ.

$\mathrm{O}$ argumento central para compreender a forma singular através da qual esse programa de capacitação docente vem se consolidando reside em seu próprio projeto educativo, que estimula a reflexão sobre o preparo do professor, as inquietações, as contradições e as necessidades da escola e de seus membros, ao mesmo tempo em que traz para o campo pedagógico novas formas de relação com a prática docente, abrindo espaço para (re)criar as relações alunos/professores, escola/sociedade. Ou seja, contribuir para construir a identidade do professor-pesquisador é aceitar, cotidianamente, o desafio de desenvolver uma cultura de pesquisa, no espaço da Escola, sem se sobrepor à lógica e aos princípios que conformam o processo de ensino-aprendizagem.

\section{Referências}

BRUNER, J. S., 1978. O Processo da Educação. São Paulo: Companhia Editora Nacional.

DEMO, P., 1985. Introdução à Metodologia da Ciência. São Paulo: Atlas.

DEMO, P., 1991. Pesquisa - Princípio Científico e Educativo. São Paulo: Cortez.

DEMO, P., 1996. Educar pela Pesquisa. Campinas: Editores Associados.

DURHAM, E. R., 1993. O sistema federal de ensino superior: problemas e alternativas. Revista Brasileira de Ciências Sociais, 23:5-37.

MARTINS, M. I.; SORIO, R. E. \& VELLOZO, V. R., 1996. Reflexões sobre o princípio da indissociabilidade ensino-pesquisa na área do ensino técnico em saúde: uma contribuição. Formação de Pessoal de Nível Médio para a Saúde: Desafios e Perspectivas. (Escola Politécnica de Saúde Joaquim Venâncio, org.), pp. 73-83, Rio de Janeiro: Editora Fiocruz.

MINAYO, M. C. S., 1992. O Desafio do Conhecimento: A Pesquisa Qualitativa em Saúde. São Paulo: Editora Hucitec/Rio de Janeiro: Abrasco.

PAOLI, N., 1988. O princípio da indissociabilidade do ensino e da pesquisa: elementos para uma discussão. Cadernos Cedes, 22:27-52.
PEDUZZI, M. P., 1997. Mudanças Tecnológicas e seu Impacto no Processo de Trabalho em Saúde. Texto elaborado para o Seminário: A Formação Técnica em Biotecnologia: Perspectivas no Mundo do Trabalho. Rio de Janeiro: Escola Politécnica de Saúde Joaquim Venâncio/Fundação Oswaldo Cruz. (mimeo.)

PEIXOTO, M.C., 1992. Associação ensino-pesquisa na universidade: caminhos de um discurso. Educação e Sociedade, 41:126-140.

STRUCHINER, M. \& MARTINS, M. I., 1994. Boletim Informativo PAETEC, 1:12.

VALLE, R., 1997. Mudanças Tecnológicas na Indústria e seus Efeitos sobre o Trabalho. Texto elaborado para o Seminário: A Formação Técnica em Biotecnologia: Perspectivas no Mundo do Trabalho. Rio de Janeiro: Escola Politécnica de Saúde Joaquim Venâncio/Fundação Oswaldo Cruz. (mimeo.)

VELlOZO, V., 1997. A Pesquisa no Ensino Técnico: Em Busca de uma Metodologia Integradora. Relatório Final (versão preliminar). Rio de Janeiro: Fundação Oswaldo Cruz/Fundação de Amparo à Pesquisa do Rio de Janeiro. (mimeo.) 